\title{
LA EXPLOSIÓN DE LA ENSEÑANZA ONLINE TRAS LA PANDEMIA - BASES EPISTEMOLÓGICAS
}

Desde una educación para una Sociedad Industrial centrada en la producción a una Educación para una Sociedad Digital centrada en el hombre

\author{
Dr. Selín Carrasco ${ }^{1}$ \\ Dra. Silvia Baldivieso ${ }^{2}$
}

\begin{abstract}
Resumen:
La Pandemia del corona virus es la turbulencia que acerca la Era Digital de manera brusca a los ciudadanos, los estudiantes y profesores lo viven de manera imprevista, muchos como si nunca hubiesen escuchado acerca de las posibilidades de enseñar o estudiar online. Esto hace necesaria la presentación de una epistemología que muestre que la educación online no es una moda, ni una imposición forzada, ni una mala jugada del capitalismos, la educación con fuerte apoyo online es la educación propia de la Era Digital y hay una serie de pensadores que así lo sostienen. Este artículo pretende mostrar una propuesta de estructura conceptual que soporta en primer lugar a la Era Digital, y después a la educación necesaria para desarrollarse como individuo en ese contexto.
\end{abstract}

Palabras-llave: Hipermundo. Educación. Educación online. Epistemología.

\section{Resumo:}

A pandemia do corona vírus é a turbulência que cerca a era digital de maneira brusca, atingindo os cidadãos, estudantes e professores, que a vivem de maneira imprevista, muitos como se nunca tivessem escutado sobre as possibilidades de ensinar ou estudar online. Isso faz necessária a apresentação de uma epistemologia que mostre que a educação online não é uma moda nem uma imposição forçada, nem uma má jogada dos capitalismos, a educação com forte apoio online é a educação própria da era digital e há uma série de pensadores que assim o sustentam. Este artigo procura mostrar uma proposta de estrutura conceptual que suporta, em primeiro lugar, a era digital e depois a educação necessária para se desenvolver como indivíduo nesse contexto.

Palavras-chave: Hipermundo. Educação. Educação online. Epistemologia.

\begin{abstract}
:
The Corona Virus Pandemic is the turbulence that brings the Digital Age abruptly closer to citizens, students and teachers, who experience it unexpectedly; many as if they had never heard of the possibilities of teaching or studying online. This requires the presentation of an epistemology showing that online education is not a fad, nor a forced imposition, nor a bad move of capitalism; education with strong online support is the education of the Digital Age, and there are a series of thinkers who hold it that way. This article tries to show a proposal of
\end{abstract}

\footnotetext{
${ }^{1}$ Universidad Nacional de San Luis.

${ }^{2}$ Universidad Nacional de San Luis.
} 
conceptual structure that supports in the first place the Digital Age, and then the education necessary to develop people, as an individual in that context.

Key Words: Hiperworld. Education. Online education. Digital era. Epistemology.

\section{Introducción}

Año 2020, una turbulencia brutal afecta todas las planificaciones estratégicas de empresas, universidades, gobiernos. Una ola de contagios de un nuevo virus derriba los planes mejor planificados y las seguridades políticas de todos los entornos consolidados, aparentemente la historia no ha terminado, resuenan más fuertes los pronósticos de Byung Chun Hal, Yuval Harari, Noah Chomsky, Slavoj Zizek y en educación se nos aparecen fantasmas, Paulo Freire, Josep Jacotot saludando nuestras certezas derribadas.

Año 2020, mientras la sociedad industrial, basada en un darwinismo mal comprendido implanta lo que llama la ley de la selva, la ley del más fuerte, impone un desarrollo basado en el consumo, en la maraña financiera, en la explotación desmedida de lo natural y ecológico, mientras se asume al mercado como el arbitro de la vida, de la educación, de la salud y del eros, una turbulencia muestra que nuestro futuro puede ser distinto, la Era Digital comienza a mostrar sus paradigmas, sus bases epistemológicas, y podemos observar que en ella podemos sentar bases diferentes gracias en primer lugar a una bióloga que lee de manera diferente a la teoría de la evolución.

Año 2020, la Era Digital tan anunciada empieza a mostrar que es diferente a la Era Industrial pues su episteme es muy diferente. No hay una nueva Revolución Industrial, hay una nueva percepción del mundo por parte de los humanos, no percibimos solamente tres dimensiones, percibimos 5, y ello, definitivamente no es industrial.

\section{El nuevo mundo que percibimos}

Desde hace ya un par de décadas todos percibimos el mundo de manera diferente, la dirección de la oficina y de la casa han perdido su trascendencia y tiene mayor peso el correo electrónico, la página web, el número de WhattsApp, Skype o similares, la dirección en la dimensión digital ha pasado a tener mayor importancia que la física o "real".

También para conocer lugares recorremos sitios online de ciudades o paisajes y en algunos casos espectáculos como el Cirque du Soleil pueden ser vistos en Realidad Virtual, o conciertos pueden ser escuchados en vivo a miles de kilómetros, y si no has podido verlo en vivo, puedes ver las grabaciones, igual que ocurre hoy durante la pandemia con los partidos de fútbol o baloncesto grabados en servidores web. 


\section{¿Qué nos indica esto?}

Que nuestra percepción de la distancia ha cambiado, se ha hecho relativa gracias a la virtualidad, de forma similar nos ocurre con el tiempo. Viajar de manera virtual, o acudir a eventos por la misma vía se ha transformado en algo posible. Hay otra dimensión en nuestro mundo que altera nuestra perspectiva. Esta nueva dimensión es la Dimensión Digital.

El Profesor Dr. Victor Sandoval, investigador de la Ecole Central de París en investigaciones realizadas en Francia y Suecia, da cuenta del fenómeno durante los 80. A esta nueva percepción del mundo la llama Hipermundo, un espacio de 5 dimensiones, las tradicionales largo, ancho, alto; más la dimensión temporal y la dimensión digital, esta última multidimensional. El demuestra además que la dimensión digital, soportada por la infraestructura digital que va cubriendo el mundo, hace relativos a la distancia y al tiempo.

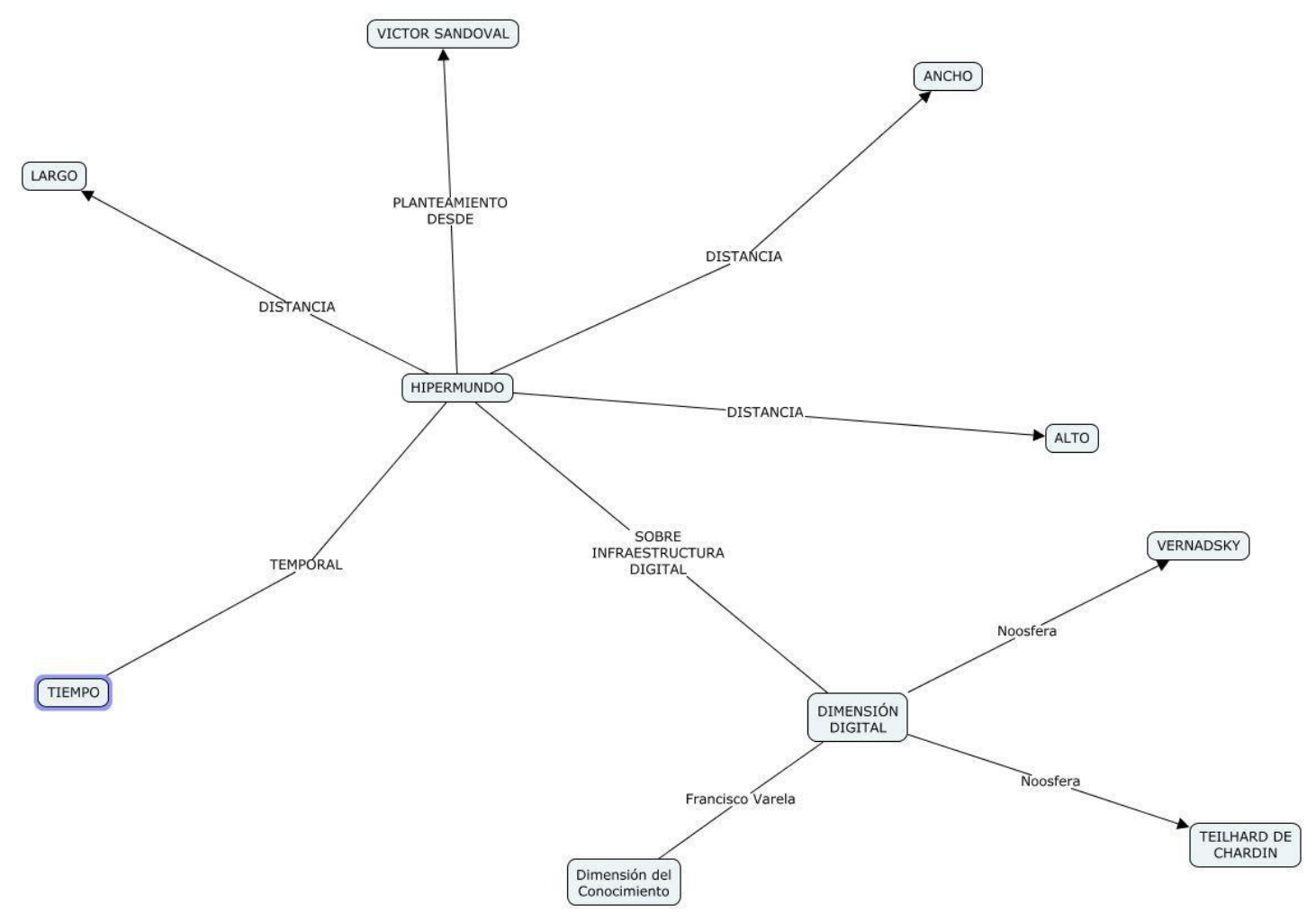

Fonte: Autores.

Fig. 1.- Mapa conceptual hipermundo

La figura 1 muestra una propuesta del concepto hipermundo, la concepción general de Victor Sandoval, y la Dimensión Digital desde tres pensadores, Francisco Varela que la llamó Dimensión del Conocimiento y Vernadsky y Teilhard de Chardin que hablaron de Noosfera, es decir, la dimensión del conocimiento que envuelve a la biosfera. 
Se fortalece la noción de Hipermundo por sobre la de Cyberespacio. Se evita expresamente la noción de Ciberespacio de Negroponte al considerarla excesivamente homogeneizante debido a la separación que plantea entre la dimensión digital y las demás dimensiones, manteniendo diferentes niveles de desarrollo entre ellas. Esta separación sostiene la hegemonía de las potencias tradicionales también en dicho espacio, sostiene la brecha social, cultural y financiera.

El Hipermundo integra todas las dimensiones que considera, en una amalgama que avanza integrada, con énfasis en lo social y en el desarrollo humano tanto local como global, abriendo posibilidades a una reconsideración de lo existente, elemento que analizaremos más adelante.

La relatividad de la distancia también nos obliga a pensar de una manera totalmente nueva la relación entre nosotros humanos y a modificar el concepto de "presencialidad". Ahora podemos hablar de "presencialidad digital" o "presencialidad física”, lo que tiene repercusiones fuertes en Salud y Educación en especial.

El Hipermundo sería entonces el soporte de la Era Digital, de la Sociedad de los Conocimientos, y a su vez está basado en una epistemología propia, muy diferente de la que soportó a la Sociedad Industrial. Nuestro principal problema perceptivo hoy es la consideración de la Era Industrial como una forma de organización social aún válida, y pensar muchos de sus elementos como paradigmáticos del desarrollo humano, tal como se hace lamentablemente con la escuela y la educación.

Las Tecnologías de la Información y las Comunicaciones (TIC) son la Infraestructura que nos han permitido generar el cambio de percepción. 


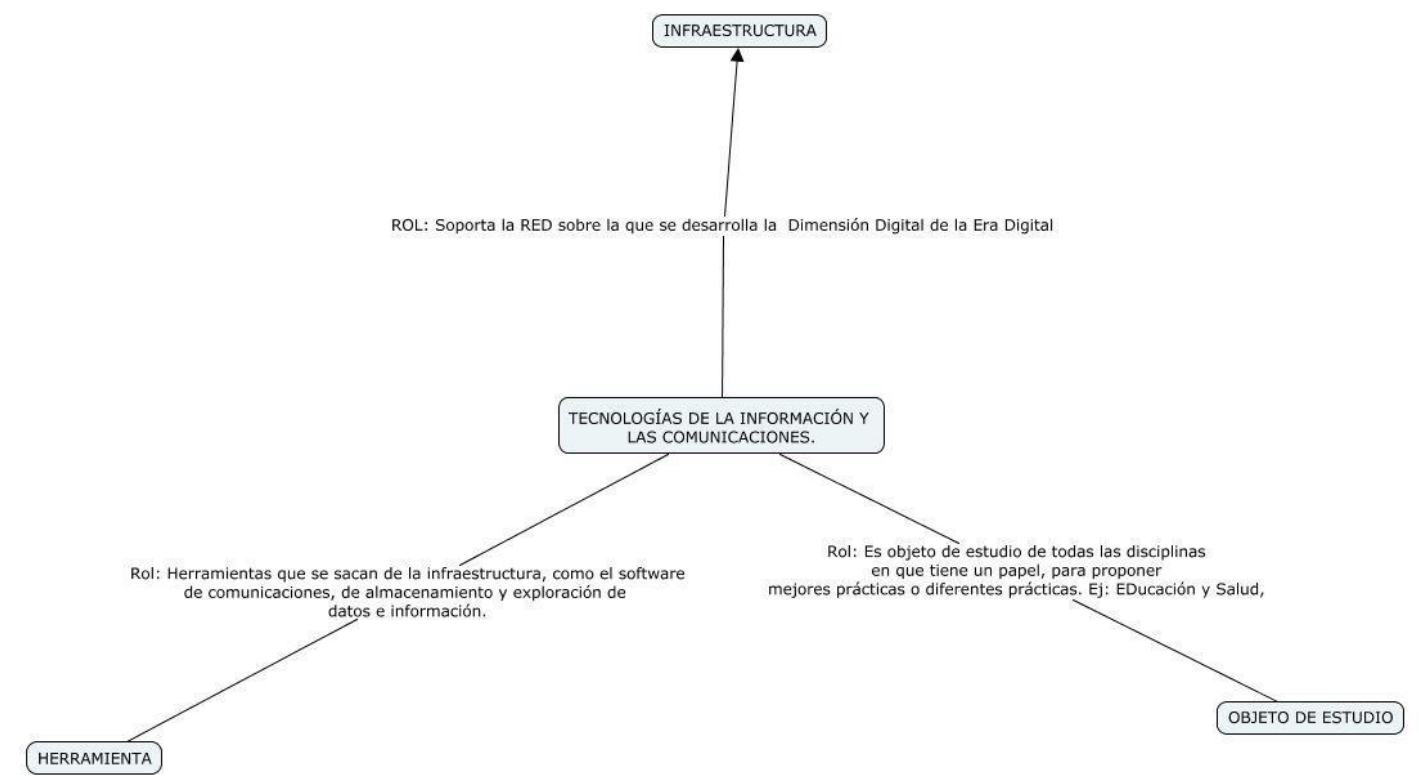

Fonte: Autores.

Fig. 2 Roles de las TIC

La Figura 2 muestra una estructura conceptual acerca del rol de las tecnologías de la Información y las Comunicaciones según postuló el Dr. Jean Francois Cerisier, Director del Master en Ingeniería de los Medios Educativos (EUROMIME) de la Universidad de Poitiers (Francia).

La importancia fundamental de las TIC, es entonces su rol de INFRAESTRUCTURA que soporta al hipermundo, a la Era Digita y, a la Sociedad del Conocimiento.

La Sociedad Industrial se ha desarrollado desde medidos del siglo XIX principalmente bajo los conceptos de la Teoría de la Evolución según planteaba Charles Darwin, la evolución del más "apto", la selección natural del más capaz, o en otras palabras la que se dió en llamar la "ley de la selva". Ello justificaba los modelos de sociedad, de economía y de negocios que se dieron durante ese período. El modelo económico capitalista es un ejemplo basado en el triunfo de los más "aptos" para generar ganancias de sus empresas en detrimento de los que solo disponían para vender su fuerza de trabajo. Bajo este paradigma se santifica el concepto de "trabajo", se crea un tipo de escuela competitiva y meritocrática, un modelo de enseñanza y toda una sociedad.

El nacimiento de la escuela de la Sociedad Industrial se refleja en la obra del escritor Charles Dickens, los niños que no podían ser cuidados por sus padres que trabajaban 7 dias a la semana, 12 horas diarias, eran encerrados y formados para ser "útiles a la sociedad", "disciplinados y obedientes miembros de ella", y que de esa forma pudieran comenzar a trabajar 
a partir de los 5 o 6 años desenredando telares o llevando carritos de mineral en los túneles más estrechos de las minas, limpiando máquinas etc. El objetivo de la escuela de la Sociedad Industrial nunca fue el desarrollo de las personas, sino su disciplinamiento para que posteriormente fueran explotados en las empresas de su tiempo sin reclamos, sin rebeldías (teoría crítica reproductivista de la educación).

La pizarra o pizarrón, inventado también en esos años, que aparece reemplazando la pizarra individual que usaba cada niño, era considerado una "máquina" de enseñar, pues permitía a los profesores entregar una clase uniforme a varias decenas de estudiantes que deberían aprender lo mismo y ser calificados de igual manera.

La Sociedad Digital tiene una nueva lectura de la Teoría de la Evolución, la propugnada por la Dra. Lynn Margulis de la Universidad de Massachussets.

La teoría de la simbiogénesis resulta revolucionaria y atractiva por muchos motivos, entre otros porque coloca la cooperación entre organismos distintos en el centro del proceso evolutivo. Para quienes han estudiado la evolución en la enseñanza secundaria, la palabra que siempre aparece al referirse al darwinismo es la de "lucha", y si no "competencia"; en parte se debe a los términos elegidos para exponer las versiones más simplistas de la teoría de la evolución. Quizás la resistencia a la teoría de la simbiogénesis tiene que ver con la necesidad de un cambio de vocabulario. Lynn Margulis (2014), Revista Macrobiótica, Mujeres en Biología: Universidad de Zaragoza (UNIZAR).

A pesar de la resistencia, que encontró en el medio tradicional, al punto que no le dejaban salas para hacer sus conferencias y era bloqueada en revistas y congresos, sus propuestas son cada vez más vigentes y hay evidencia de su validez. La resistencia que encuentra es fundamentalmente política, cuesta mucho cambiar el concepto de que evolucionamos por colaborar y no por competir.

De hecho la colaboración entre humanos es muy fuerte, hay múlitples ejemplos de ello en la Sociedad de los Conocimientos, me gusta siempre visualizar el alcance que han logrado proyectos colaborativos como Wikipedia, la mayor enciclopedia mundial, Moodle una de las mejores plataformas educativas LMS y en general los desarrollos a través de Sourceforge (espacios de desarrollo colectivo y colaborativo).

Los educadores somos testigos de lo positivo del aprendizaje colaborativo en todos los niveles de educación.

Las propuestas de Lynn Margulis tuvieron un precedente en Kropotkin quien expresó en su tiempo, lo siguiente:

Comencé a abrigar serias dudas, que más tarde no hicieron sino confirmarse, respecto a esa terrible y supuesta lucha por el alimento y la vida dentro de los límites de una misma especie, que constituye un verdadero credo para la mayoría de los darwinistas.

Exactamente del mismo modo comencé a dudar respecto a la influencia dominante que ejerce esta clase de lucha, según las suposiciones de los darwinistas, en el desarrollo de las nuevas especies. 
Cuando más tarde las relaciones entre el darwinismo y la sociología atrajeron mi atención, no pude estar de acuerdo con ninguno de los numerosos trabajos que juzgaban de un modo u otro una cuestión extremadamente importante. Todos ellos trataban de demostrar que el hombre, gracias a su inteligencia superior y a sus conocimientos puede suavizar la dureza de la lucha por la vida entre los hombres pero al mismo tiempo, todos ellos reconocían que la lucha por los medios de subsistencia de cada animal contra todos sus congéneres, y de cada hombre contra todos los hombres, es una "ley. natural". Sin embargo, no podía estar de acuerdo con este punto de vista, puesto que me había convencido antes de que, reconocer la despiadada lucha interior por la existencia en los límites de cada especie, y considerar tal guerra como una condición de progreso, significaría aceptar algo que no sólo no ha sido demostrado aún, sino que de ningún modo es confirmado por la observación directa. (KROPOTKIN, 2016, Introducción).

Podemos comenzar a analizar entonces en la Era Digital, soportándonos en diferentes paradigmas y parámetros. De igual forma, posteriormente, iremos tocando los temas relacionados directamente con educación desde cada soporte epistemológico. De partida entonces, desde Lynn Margulis tomamos la necesidad de la formación colaborativa para los humanos viviendo en la Sociedad Digital.

Las dos imágenes próximas nos muestran las bases conceptuales intrinsecas de la Sociedad Industrial y de la Sociedad Digital.

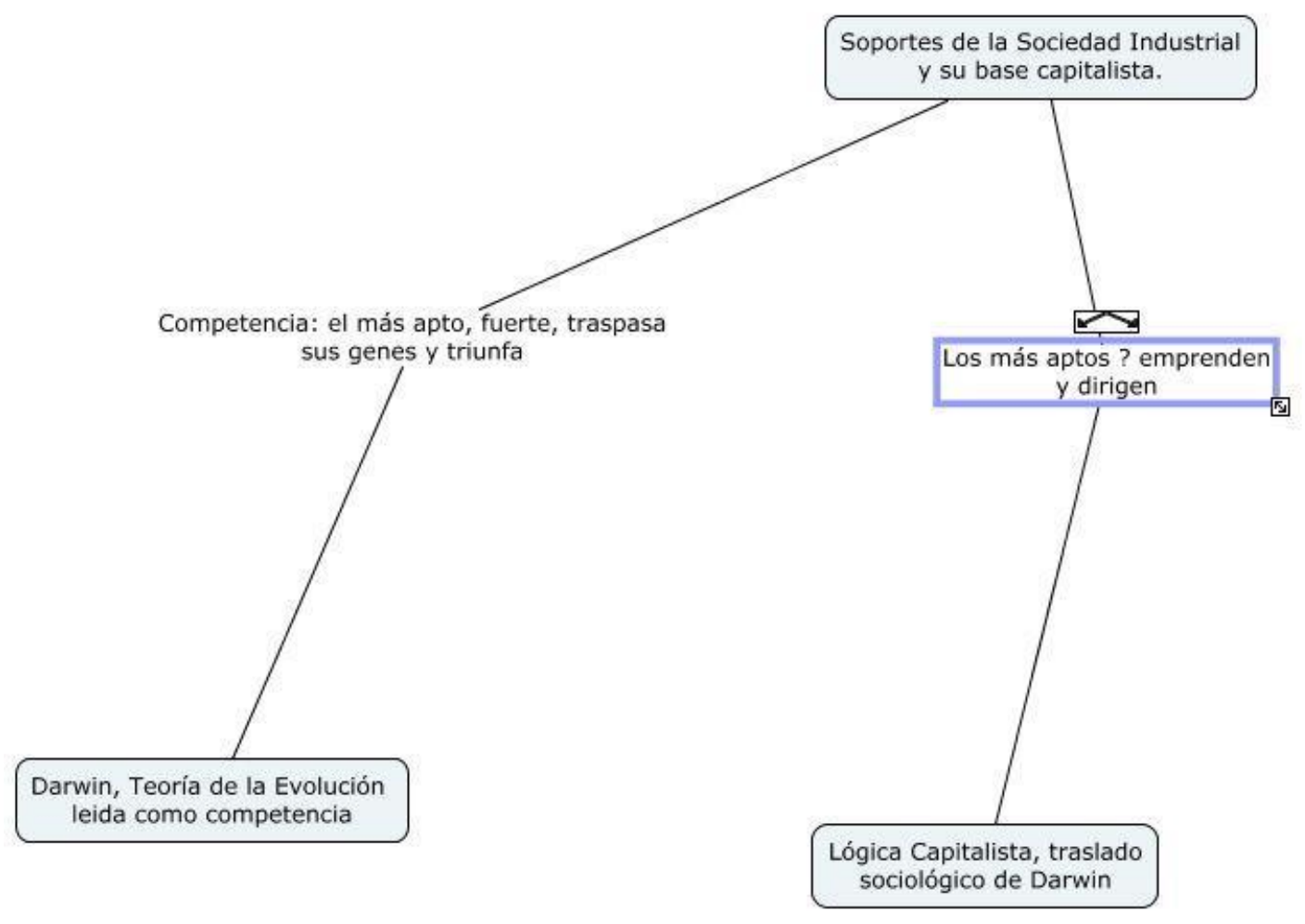

Fonte: Autores.

Fig. 3 Bases conceptuales intrínsecas de la Sociedad Industrial 


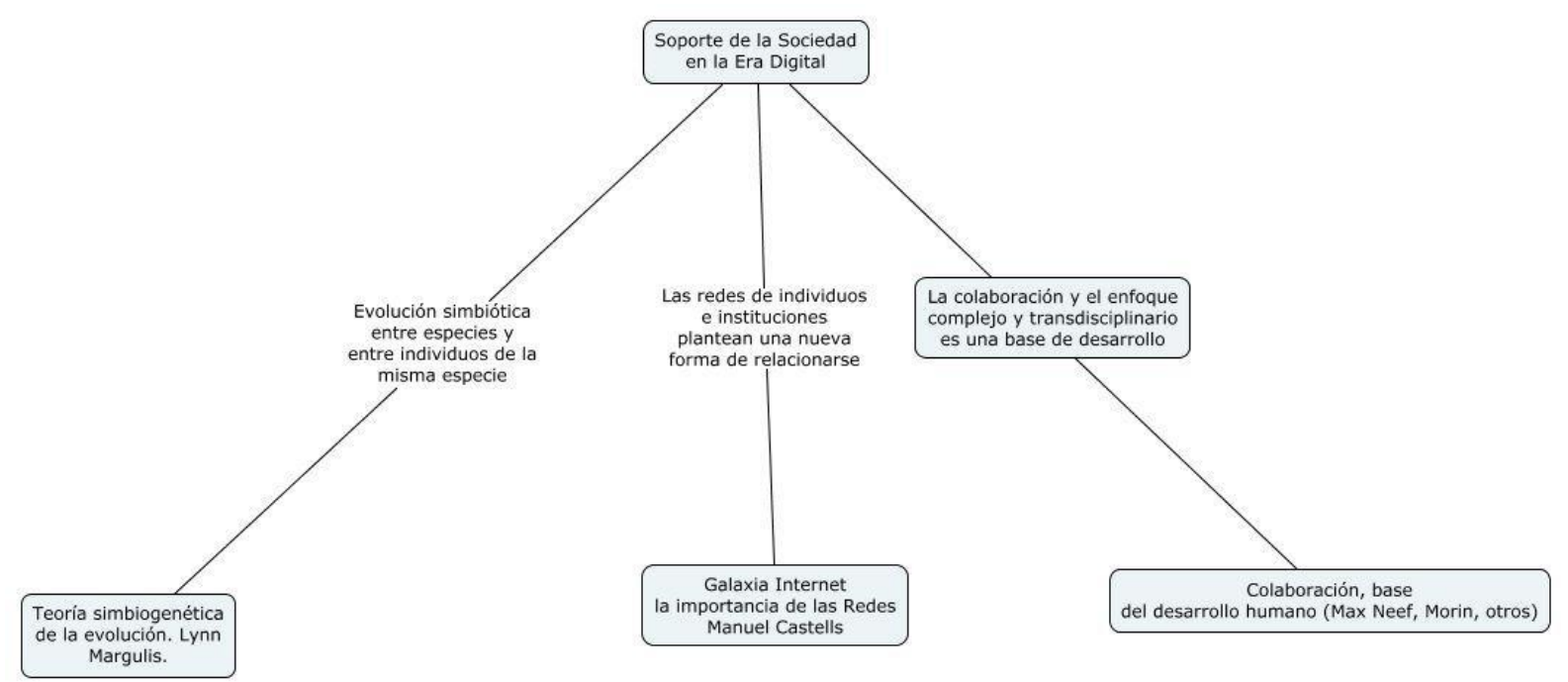

Fonte: Autores.

Fig. 4 Bases conceptuales de la Sociedad Digital.

Los dos gráficos anteriores nos muestran el gran cambio paradigmático entre las sociedades provenientes de la Revolución Industrial y sus antecedentes anteriores con las nuevas sociedades que se están generando sobre la infraestructura digital que soportan al Hipermundo.

Pero esos cambios no son los únicos que disparan y sostienen un nuevo espacio de desarrollo humano, los teóricos que advierten de los grandes riesgos que conlleva seguir con las propuestas industriales, uno de ellos es Zygmunt Bauman quién en "Modernidad Líquida" y en sus 25 libros siguientes advierte el camino por el que nos lleva la política neoliberal y el desarrollo humano medido en términos de consumo.

Nos presenta una sociedad líquida en la que los humanos necesitamos nadar de manera permanente para sobrevivir a flote en espacios que se modifican constantemente, para acomodarse a las exigencias del mercado, que requiere generar mayores rentabilidades (a los poseedores del capital y de sus circuitos de movimientos financieros).

Chile fue un ejemplo de un país que liquifacó su sociedad bajo la dictadura militar y que obligó a sus ciudadanos a nadar por su vida, o a apoyarse en otros para sobrevivir mientras entregaba islas seguras para desarrollarse a sus acólitos, creando un país líquido que aún subsiste de igual manera.

Desde el centro de EEUU, Noah Chomsky se suma a las voces críticas teorizando sobre la amenaza que supone la falta de democracia impulsada desde los países capitalistas, en 
especial en el propio y postula que los objetivos económicos de dichos grupos socavan el bienestar humano e impiden las propuestas que llevan a ello.

Chomsky afirma que para la mayor parte de la población, incluso en un país tan rico como EE. UU., los sueldos se han estancado o han descendido en cuanto a su valor efectivo, a lo largo de los últimos 25 años, mientras que el horario y la inseguridad laboral han crecido mucho [...] La economía mundial ha descendido en el mismo periodo de tiempo (de forma considerable) y ha ido a una mayor concentración [...] para una gran parte de la población mundial, las condiciones son horrorosas (dumping social en India, Bangla Desh, Sudamérica, Sudeste asiático, etc.) y a menudo se deterioran, y, lo que es más importante,[...] la correlación entre el crecimiento económico y el bienestar social que a menudo se ha dado (por ejemplo, durante la posguerra o la preliberalización) se ha truncado.

En general los teóricos críticos del capitalismo ven como la inercia en la dirección que proponen los teóricos de la Sociedad Industrial implican graves peligros para la continuidad de la especie humana; un ejemplo es la opinión del sociólogo crítico contra la tecnología, Paul Virilio, este pensador desarrolló lo que llama "modelo de guerra" en la ciudad moderna y la sociedad humana en general e inventó el término 'dromología', que significa que la lógica de la velocidad es la base de la sociedad tecnológica.

Actualmente la noción de velocidad social sigue siendo investigada por el Dr. Hartmut Rosa advirtiendo que la Aceleración social tiene consecuencias éticas y políticas, en una sociedad de alta velocidad desincronizada, con diferentes velocidades dependiendo de los segmentos sociales.

Muchos otros teóricos actuales o recientes ven la continuidad del desarrollo del sistema actual, sin cambios profundos, como el acercamiento a un abismo social, cada vez más riesgoso.

En la próxima estructura conceptual esquematizamos las diferentes líneas de advertencias de estos críticos actuales, y posteriormente presentamos ejes de sus perspectivas. 


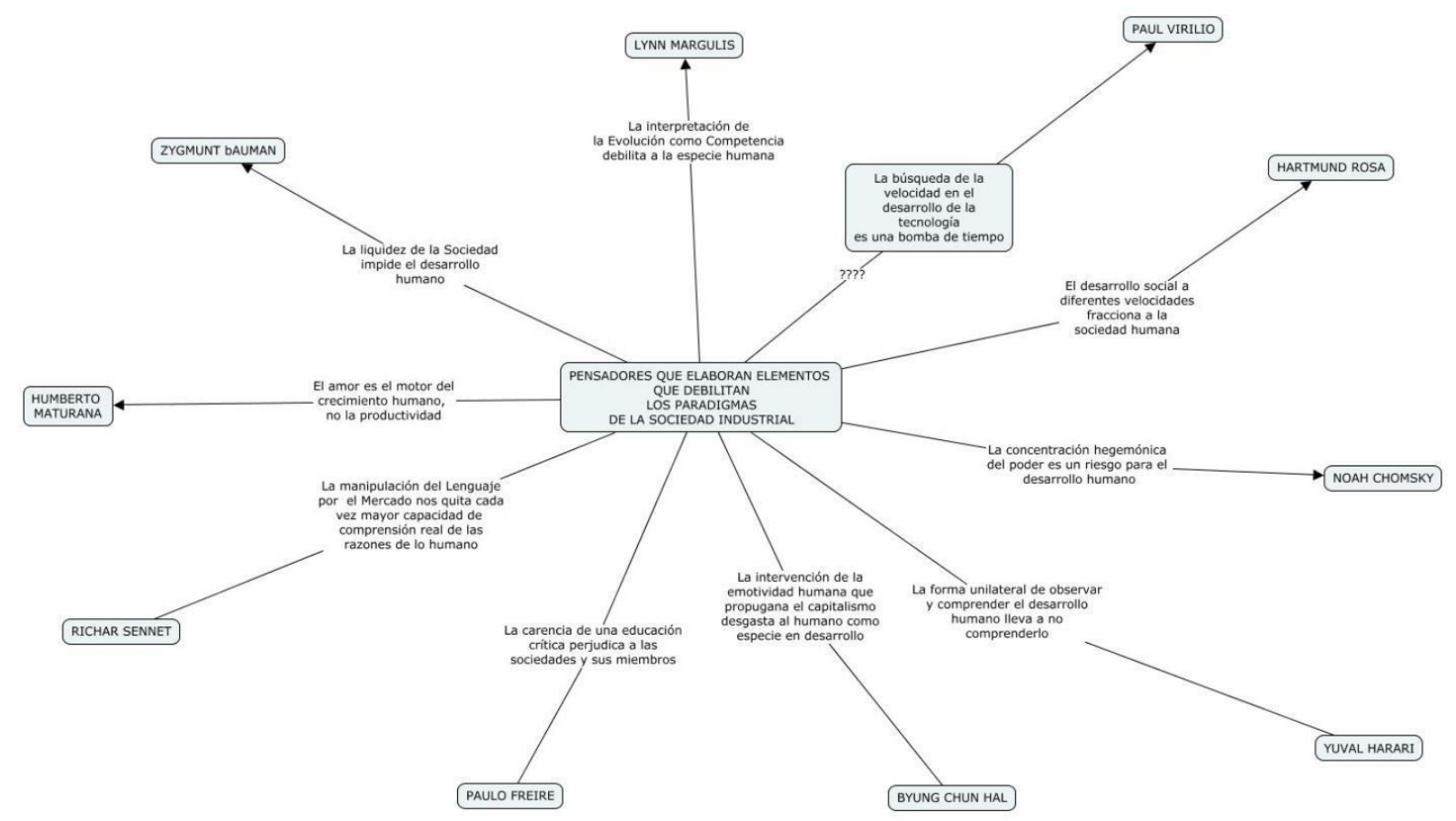

Fonte: Autores.

Fig. 5- Un recorrido por los teóricos que advierten acerca de los riesgos de mantener la inercia de desarrollo de la Sociedad Industrial

\section{Teóricos críticos a la inercia de la Sociedad Industrial}

\section{Humberto Maturana}

Como biólogo desarrolló el concepto de autopoiesis para diferenciar seres con procesos vitales: la biología del conocer. Posteriormente, y como filósofo trabaja el concepto de matríztica y enfatiza en la necesidad de privilegiar el amor como elemento fundamental en el desarrollo del humano como tal. Critica al sistema actual por su imposibilidad de centrarse en el desarrollo de la individualidad de las personas.

\section{Richard Sennet}

Sociólogo, pragmático, profundiza en el sentido del lenguaje y en la forma en que el sistema actual lo desnaturaliza buscando corromper el caráter del individuo, llevándolo a aceptar lo que le dicen los estratos dominantes. Plantea especialmente que la dirección de desarrollo a la que nos lleva el sistema capitalista, impulsa la fragmentación de las experiencias, $\mathrm{y}$ hace peligrosa la flexibilidad que nos prometieron que iba a mejorar la vida, $\mathrm{y}$ ha acabado llevando el trabajo hasta cada minuto y rincón de nuestra vida privada generando una explotación ilimitada y voluntaria.

El capitalismo moderno funciona colonizando la imaginación de lo que la gente considera posible. Marx ya se dio cuenta de que el capitalismo tenía más que ver con la apropiación del entendimiento que con la apropiación del trabajo. Facebook es la penúltima apropiación de la imaginación: lo que veíamos como útil ahora se revela como una manera de meterse en la conciencia de la gente antes de que podamos actuar. Las instituciones que se presentaban como liberadoras se convierten en controladoras. En nombre de 
la libertad, Google y Facebook nos han llevado por el camino hacia el control absoluto.

Paulo Freire

https://elpais.com/elpais/2018/08/09/eps/1533824675_957329.html

Desde Brasil, plantea que la educación característica y propia de la sociedad industrial es la que el llama "Educación Bancaria", el profesor (el sistema), deposita conocimientos en la comprensión del estudiante y espera que este les devuelva posteriormente, con una interpretación idéntica o cercana a la que el profesor le ha entregado, limitando de esta manera la capacidad de desarrollo del estudiante a los límites que el profesor le fija.

Freire comprende que la educación de la sociedad industrial busca formar en especial en la reproducción de contenidos, la obediencia y en la disciplina, cerrando los espacios críticos y/o de libertad del estudiante.

\section{Byung Chul Han}

Sociólogo coreano, critica al capitalismo, a la sociedad del trabajo, a la tecnología vectorial y a la hipertransparencia. Llama a la sociedad industrial actual: la «sociedad del cansancio» (Müdigkeitsgesellschaft), o la «sociedad de la transparencia» (Transparenzgesellschaft). El desarrollo actual se centra en la dicha «transparencia» como norma cultural, creada por las fuerzas del mercado neoliberal, para conocer y explotar mejor a todos los posibles "clientes", él entiende que se busca un insaciable impulso hacia la divulgación voluntaria de todo tipo de información. Ello permitiría controlar los mercados por sobre los intereses de las personas, llevando a que sus intereses sean los de las empresas que le quieren hacer "comprar".

Según Han, los dictados de la transparencia imponen un sistema totalitario de apertura a expensas de otros valores sociales como la vergüenza, el secreto y la confidencialidad.

En su obra "La sociedad del cansancio caracteriza a la sociedad actual como un paisaje patológico de trastornos neuronales, depresión, déficit atencional e hiperactividad, trastorno límite de la personalidad y agotamiento (burnout). Afirma que no se trata de «infecciones», sino de «infartos», que no son causados por un fenómeno negativo de inmunología en las personas sino por un «exceso de positividad». Donde la "positividad" es una sensación forzada por el contexto social de igual manera que competir, liderar, etc.

En su libro "La agonía del Eros", Han se extiende a lo que él denomina «pérdida del deseo», la desaparición de la capacidad para dedicarse al «otro», al extraño, al no-yo. La transparencia llevada al máximo hace perder la capacidad de ver la otredad, la situación del humano centrado en si mismo, imposibilita su desarrollo, su crecimiento. 
Giramos alrededor de nosotros mismos, nos restringimos en nuestra mismidad, incapaces de construir relaciones con los demás. Incluso el amor y la sexualidad se impregnan de este cambio: socialmente, el sexo, la pornografía y el exhibicionismo están desplazando al amor, al erotismo y al deseo en el ojo público. (Wikipedia)

La exigencia de la homogeneidad y el aplastamiento del diferente es otra característica de la sociedad actual que genera repulsa a Byung Chul Han.

\section{Yuval Harari}

Viviendo en Israel como profesor de la Universidad Hebrea de Jerusalen hace una de las primeras miradas humanas a la propia historia del hombre, pretendiendo ser "avalórico" y reconociendo la imposibilidad de serlo y consigue mirar a través de múltiples cristales los diferentes caminos que ha seguido el desarrollo del hombre.

Harari es un pensador analítico y transdisciplinario con una lúcida mirada de la humanidad desde sus simientes hasta la actualidad y plantea peligros generados desde esa misma tendencia histórica que los humanos no hemos sido capaces de resolver.

Plantea que la religión mayor que ha existido es la actual, donde el "Dinero" ha pasado a ser el Dios más aceptado, y que lo epicúreo guía al desarrollo del humano, lo ha guiado hasta ahora, buscando una realización basada en la satisfacción del individuo ya sea de manera directa o manipulada por "guías" que le indican los caminos.

Sus libros nos permiten mirar la historia plagada de "errores" de la humanidad, las diferentes formas de equivocarse para conseguir mantenerse en caminos no conducentes al desarrollo de la especie.

\section{Hartmut Rosa}

Continuando las líneas reflexivas de Virilio respecto a los riesgos de los desarrollos cada vez a mayor velocidad de diferentes segmentos de la humanidad, critica esta aceleración creciente que llevaría al acercamiento a abismos de todo tipo.

\section{Mirando los agujeros del techo, proponemos algunas formas de cubrirlos}

De los elementos carenciales que ven estos pensadores, podemos hacer una primera propuesta educativa para la Era Digital, que ayude a resolver dichas situaciones.

Hemos visto que los problemas discutidos por los pensadores de la figura anterior, que mayormente destacan, se relacionan fundamentalmente a la invisibilidad de los otros, el excesivo aprecio por el consumo y el dinero, la falta de amor, la vulnerabilidad ante la manipulación del lenguaje, el exceso de velocidad de vida a la que lleva el consumismo. Elementos importantes para resolver dichas posiciones o evitar dicho enfoques, serían una educación que potencie la valoración de los otros, trabajo colaborativo, lectura crítica, 
emotividad y valores que apoyen de desarrollo de los humanos como individuos y como especie.

Teóricos críticos que proponen caminos alternativos a los seguidos en la Sociedad

\section{Industrial}

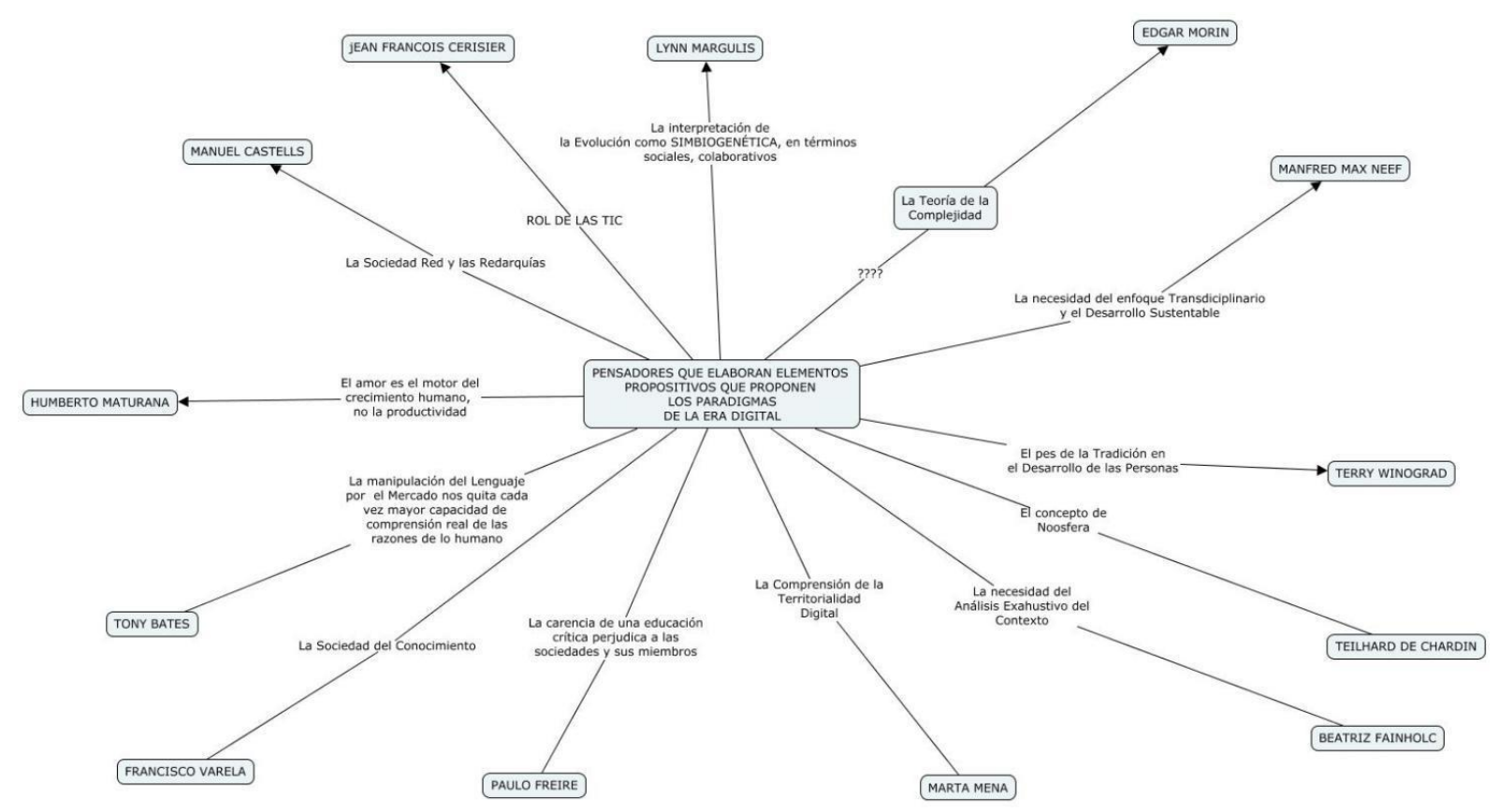

Fonte: Autores.

Fig 6 - Un recorrido por los teóricos que entregan sustento epistemológico a una Sociedad Digital en una Era Digital

\section{Lynn Margulis}

Otra vez Lynn Margulis, pues es una base de pensamientos diferente. No es lo mismo plantear procesos educativos, formativos cuando la base de la vida es la competencia, que cuando lo es la simbiósis, la colaboración.

De acuerdo a algunas propuestas publicadas entre 2018 y 2020, algunas de las ventajas de los hombres de Cromagnon sobre sus vecinos Neanderthales fueron la división del trabajo, la cacería en grupos colaborativos de mayor tamaño entre otras. O sea, encontramos correlación entre los documentos de Lynn Margulis y evidencias arqueológicas recientes (Wikipedia).

Últimas investigaciones refuerzan las propuestas de la Dra. Lynn Margulis,

La simbiogénesis ha ido ganando apoyo experimental: en los años 70 se descubrió que los genes de las mitocondrias y los cloroplastos se parecían más a los de ciertas bacterias que a los de las células eucarióticas a las que pertenecen. Y recientemente, un nuevo estudio ha venido a prestar nueva y extensa credibilidad a la teoría de la endosimbiosis. Un equipo de investigadores dirigido por el biólogo evolutivo William F. Martin, de la 
Universidad Heinrich Heine de Dusseldorf (Alemania), ha comparado casi un millón de genes de 55 especies eucariotas y más de seis millones de genes de procariotas, un análisis exhaustivo que solo hoy es posible gracias al uso de avanzadas herramientas bioinformáticas.

La investigación, publicada en Nature el pasado agosto, rastrea el origen de los genes bacterianos que forman parte integral del ADN presente en el núcleo celular de los organismos superiores, incluidos los humanos. Y frente a la posibilidad de que estas innovaciones genéticas pudieran haberse colado en nuestras células por un largo y continuo proceso gradual de transferencia de genes al azar, los resultados muestran que, por el contrario, la huella bacteriana en nuestro ADN es el producto de un salto evolutivo brusco que corresponde a la adquisición de las mitocondrias (o de los cloroplastos, en el caso de los vegetales).

Lo que hemos mostrado es que la contribución genética de los ancestros endosimbióticos de plástidos y mitocondrias al material genético de partida del linaje eucariótico fue mucho mayor de lo que nadie había sospechado", resume Martin a OpenMind. "Los eucariotas adquirieron genes de los procariotas en el origen de la mitocondria y en el origen de los plástidos", añade, lo que supone "un clamoroso apoyo a la teoría endosimbiótica".

https://www.bbvaopenmind.com/ciencia/grandes-personajes/lynn-margulis-la-

cientifica-rebelde/ originalmente de Nature, Agosto 2019.

Somos simbióticos desde la respiración celular, ¿como no serlos en la vida diaria?

\section{Edgar Morin} completo:

Desde la página de Cátedra UNESCO Edgar Morin, extraemos un párrafo muy

$\mathrm{Su}$ pensamiento excéntrico con respecto al clima cultural europeo, caracterizado por el protagonismo del estructuralismo y el posestructuralismo, lo llevó a investigar en forma independiente y alejado de la vida académica, sobre lo que luego denominará "humana condición" y la complejidad de la identidad humana. Su preocupación por encontrar un enfoque no reduccionista de los fenómenos complejos como es el caso de lo humano y su entorno, lo impulsa a transitar distintos paradigmas en búsqueda de una plataforma, un pensar y un camino (método) que denominará "pensamiento complejo", en un contexto inédito de la relación de la humanidad con el planeta, que junto con otros pensadores, caracterizará como "era planetaria", ubicando el nacimiento de la misma en el descubrimiento de América.

... a partir de la década de los '90 centrará sus esfuerzos en proponer alternativas al déficit principal del sistema educativo, consistente en la organización fragmentaria de sus contenidos, efecto y al mismo tiempo causa del fenómeno de la hiperespecialización, cuya tendencia obstaculiza el estudio de los desafíos más urgentes de la vida planetaria que desbordan ese orden fragmentario de conocimientos. Su propuesta de articulación de saberes y su pregunta sobre cuál es la visión de transdisciplinariedad más apropiada a las circunstancias, son el eje de sus aportes a las reformas educativas del presente.

Sus propuestas de educación integral e integrada, transdisciplinaria, compleja con

vinculación de saberes es su aporte a la sociedad del futuro en la Era Digital. 


\section{Manfred Max Neef}

Sus planteamientos económicos acerca de lo necesario de la sustentabilidad de la economía le valieron el premio Right Livelihood Award considerado el verdadero Nobel de Economía, en 1983. Todas sus investigaciones y documentos relativos al desarrollo humano fueron aportes a la construcción de una nueva sociedad, diferente de la estructurada durante la Era Industrial. Posteriormente trabaja el concepto de Transdisciplina, considerando que ella es el elemento necesario para resolver la desorientación cultural que padece el mundo. En su universidad, la Austral de Chile crea y dirige un proyecto transdisciplinar, el Centro de Estudios Ambientales (CEAM), lugar en que pone en práctica sus propuestas de formación.

Por ello la transdisciplina en la formación y educación es su propuesta para la sociedad de la Era Digital.

\section{Terry Winograd}

Nos persigue nuestra tradición, es nuestra opción apoyarnos en ella o intentar huir, pero generalmente esas fugas no son exitosas. En diferentes escritos Winograd nos confronta con el hecho de que la tradición nos influye, y ello es especialmente patente en el diseño. El investigador de la Universidad de la Frontera, Dr. Gastón Sepúlveda trabajó en esta línea la influencia de la tradición en los procesos formativos, tanto desde la óptica del profesor como de la del estudiante.

Por su planteamiento de incorporar la tradición de los estudiantes en los procesos educativos, Terry Winograd es uno de los pilares de la educación para la Era Digital.

\section{Teilhard de Chardin}

Sobre la física Geosfera se encuentra cubriéndola, la Biosfera, y sobre ella, la Noosfera, el conjunto de seres inteligentes que son parte de la biosfera de la tierra. Desde los postulados iniciales de Vernadsky hasta la actualidad, este concepto ha ido siendo centro de discusión, en especial en los últimos años con el auge de Internet, que hace más patente la existencia de una capa de inteligencia sobre la tierra. Al cubrir la red, la web, todo el planeta con sus redes, podemos hablar con claridad acerca de una red inteligente por sobre el planeta. Esta red, soportada fundamentalmente por la infraestructura generada por las Tecnologías de la Información y las Comunicaciones podría posibilitar a futuro una racionalidad - intuición común, entre los humanos.

Por su propuesta de colaboración en una posible mente planetaria, los postulados de Chardin son soporte de la Era Digital. 


\section{Beatriz Fainholc}

La incorporación de lo social y lo emotivo de manera insistente en sus propuestas educativas hacen de la Dra. Fainholc un aporte a la futura educación.

Las TIC se han convertido en una fuerza de cambio cultural

Su blog, muy vivo y dinámico entrega permanentemente sus propuestas:

https://webquestorgar.blogspot.com/

\section{Marta Mena}

Los territorios digitales, espacios en la web referidos a los territorios en los mundos "reales", es un aporte a la comprensión del concepto Hipermundo. Lo territorial tiene su reflejo en el espacio pentadimensional propio de la Era Digital y ello permite comprender la necesidad de la participación de los espacios locales en una posible globalización real.

A pesar de que en un principio, la participación en los territorios digitales estuvo fuertemente frenada por la "brecha social", reflejada en la "brecha digital" y ahora esta disminuye en cuanto a participación; es necesario para significar y fortalecer nuestros espacios sociales, una masiva integración de nuestros haceres y refuerzos identitarios en un Hipermundo, en las dimensiones digitales. Existe Globalización efectiva cuando lo Local es significativo y tiene sentido y significado en lo Global

\section{Paulo Freire}

Desde Brasil, el gran investigador latinoamericano que en su comprensión nos muestra que el opresor y el oprimido puede estar dentro de nosotros, coincide con los últimos escritos del Byung Chul Han.

La educación como práctica de la libertad, título de uno de sus primeros libros es una fuerte declamación acerca de la relación libertad-educación. Su enfoque acerca de una exigencia de educación crítica, la autonomía de la escuela son estudiados, analizados y comprendidos pero muy poco aplicados.

En efecto, sus propuestas son elementos básicos imprescindibles para la formación de las personas en la Sociedad del Conocimiento base de la Sociedad Digital en la Era Digital.

En sus propuestas de construcción de conocimiento por parte del estudiante, coincide con Francisco Varela, que dice que el profesor ayuda al estudiante a construir su propio modelo de conocimiento, el que no es idéntico al del profesor, una enseñanza crítica y un aprendizaje independiente.

Freire propone la pedagogía de la pregunta, esta pedagogía se basa en la creación del conocimiento a través de preguntas, donde el alumnado tanto como el profesor o profesora 
puedan aprender de ellas y provocar un enriquecimiento recíproco; esta es una posibilidad de trabajo que se puede potenciar actualmente en muchos espacios de la naciente Era Digital.

Como el mejor exponente de una educación necesaria en espacios sociales en que el trabajo como se entiende hoy, va desapareciendo, Paulo Freire es una gran base de la educación en la Era Digital.

\section{Francisco Varela}

Un biólogo chileno preocupado por la autopoiesis y por el conocimiento. Su libro "Conocer" es un excelente resumen de los conceptos asociados a conocimiento, su propuesta de que la principal ciencia relacionada con el conocimiento es la EDUCACIÓN, pone un énfasis en la forma en que se transfieren los modelos de conocimiento de una generación a otra. Si se transfieren sin modificaciones de manera acrítica, o como diría Freire mediante educación bancaria, no hay mejoras buscadas entre generaciones. Para conseguir mejores maneras de gestionar el conocimiento, mejorarlo, potenciarlo y que existan individuos capaces de representarlo de maneras diferentes y creativas, se necesitan nuevas formas de enseñanza.

El Conocer y el Conocimiento, preocupaciones del Varela de la enacción, de la mente imbuida en un cuerpo, concepto proveniente de su práctica budista, son elementos indispensables en nuestra formación como especie que busca mejorar sus espacios evolutivos.

La neutralidad imposible del conocimiento es otro de sus grandes aportes, el conocimiento es un vector, y tiene dirección y sentido, el que trabaja con él, es el responsable de direccionarlo.

\section{Tony Bates}

Educador canadiense de educadores, geneticamente profesor y propiamente profesor de la Era Digital como el mismo lo afirma desde su web personal. Dedicado a la enseñanza web desde hace más de 30 años, continúa aportando en dicha dirección, para fortalecer procesos educativos integrados en la "no distancia" de Internet.

Sus libros han sido útiles a generaciones de educadores que buscan espacios de democratización de los procesos educativos, del conocimiento y de la información. Sus planteamientos acerca de como integrar la educación a los procesos vitales de forma permanente lo hacen un pilar de la educación en la Era Digital.

\section{Humberto Maturana}

El "ser", el "hacer", el "lenguajear", cu curiosidad y osadía en la exploración del desarrollo del humano lo hacen una base de los pensamientos de la Era Digital, su decidida postura acerca del "amor" como fuerza evolutiva e integradora de la especie, obligan a repetir 
su nombre entre los que desestructuran la Sociedad Industrial y los que construyen la epistemología de la Era Digital.

Según Wikipedia, plantea “...la idea de la evolución de las especies por medio de la deriva natural, basada en la concepción neutralista de que la manera en que los miembros de un linaje realizan su autopoiesis se conserva transgeneracionalmente, en un modo de vida o fenotipo ontogénico particular, que depende de su historia de interacciones, y cuya innovación conduciría a la diversificación de linajes."

Es importante considerar las diferentes posturas en relación a la Teoría de la Evolución pues resaltan la existencia de caminos diferentes y nos aleja de los postulados absolutos de camino único, tanto en ideologías políticas como económicas.

\section{Manuel Castells}

Obtuvo el Premio Holberg por haber «dado forma a nuestra comprensión de la dinámica política de las economías urbanas y globales en la sociedad red». Autor de "Galaxia Internet" describe y prevee la forma en que la infraestructura digital del Hipermundo modifica el quehacer humano y crea nuevos tipos de relaciones. El reemplazo de las jerarquías por las redarquías es un concepto que traspasa las estructuras de la Sociedad Industrial a las propias de la Sociedad Digital.

Castells estudia también la dinámica de conformación de las ciudades según los desplazamientos obreros, según las necesidades de trabajadores en los espacios urbanos. Ello hace que sus metodologías de análisis sean hoy especialmente interesantes, al encontrarnos en un momento en que podremos ver desplazamientos internos en las ciudades al aparecer un nuevo concepto de trabajo por el reemplazo de humanos por robots e inteligencia artificial.

Su estudio "La era de la información" es uno de los textos fundantes de lo que hoy damos en llamar Era Digital.

Su descripción de la Era de la Información:

Es un periodo histórico caracterizado por una revolución tecnológica centrada en las tecnologías digitales de información y comunicación, concomitante, pero no causante, con la emergencia de una estructura social en red, en todos los ámbitos de la actividad humana, y con la interdependencia global de dicha actividad. Es un proceso de transformación multidimensional que es a la vez incluyente y excluyente en función de los valores e intereses dominantes en cada proceso, en cada país y en cada organización social. Como todo proceso de transformación histórica, la era de la información no determina un curso único de la historia humana. Sus consecuencias, sus características dependen del poder de quienes se benefician en cada una de las múltiples opciones que se presentan a la voluntad humana. (En La Era de la Información, I).

Sus postulados acerca de la importancia de las redes en las sociedades humanas actuales es una de las bases de la educación de la Era Digital. 


\section{Jean Francois Cerisier}

Como Director de la Maestría en Ingeniería en Medios Educativos describió los diferentes roles de las Tecnologías de la Información y las Comunicaciones, modificando los conceptos que hasta ese momento hablaban de las "herramientas digitales" o de la necesidad de “incluir a las Tecnologías de la Información y las Comunicaciones en la Educación”.

Su separación clara de los roles en Infraestructura, Herramienta y Objeto de Estudio, permite entender de forma clara la interacción de ellas con lo social, dándo importancia al rol de infraestructura que es la base que conforma la Era Digital. La Dimensión Digital del Hipermundo descansa justamente sobre la infraestructura digital, las herramientas son sacadas de dicha infraestructura y necesitamos estudiar tanto la infraestructura como la herramienta para su óptima utilización en nuestras diferentes profesiones y quehaceres.

Esta forma de comprender a las tecnologías es básica para su aplicación en la educación en la Era Digital.-

\section{Grupo-espacio iEducativa - UNSL}

Por último nos parece oportuno señalar tambien el grupo . espacio ieducativa de la Universidad Nacional de San Luis al que pertenecemos los autores de este artículo.

Dicho grupo desde hace algunos años viene interrogándose por el aporte de la formación en investigación en educación a la construcción de una nueva realidad socioeducativa y a partir de ello, entre otras múltiples aristas, cuestionando el aporte de la ciencia y la epistemología occidental en la conformación de la sociedad actual y visualizando en la era digital, una oportunidad de habitar nuevos espacios, desarrollar nuevos procesos y hacer propias las tecnologías y el hipermundo para atender viejas deudas con la producción de conocimientos desde el reconocimiento de la diversidad epistémica y sociocultural, que rescaten los saberes plurales que restituyan dignidad y protagonismo a los diferentes grupos y saberes plurales.

Reflexionamos así en torno a la necesidad de mantener una vigilancia epistemológica en torno al uso que damos a los medios y oportunidades que otorga la era digital y la oportunidad de articular el trabajo por la diversidad epistémica, a movimientos críticos nacidos en el espacio de lo tecnológico y digital que promueven la democratización del acceso al conocimiento y la apertura de las agendas y procesos de investigación (Ciencia abierta y ciudadana, por ejemplo). (BALDIVIESO, 2019, p.85). 
Al igual que en el apartado anterior, en base a las propuestas realizadas por los pensadores antes nombrados, propondremos algunos elementos a incorporar a los procesos educativos propios de la Era Digital.

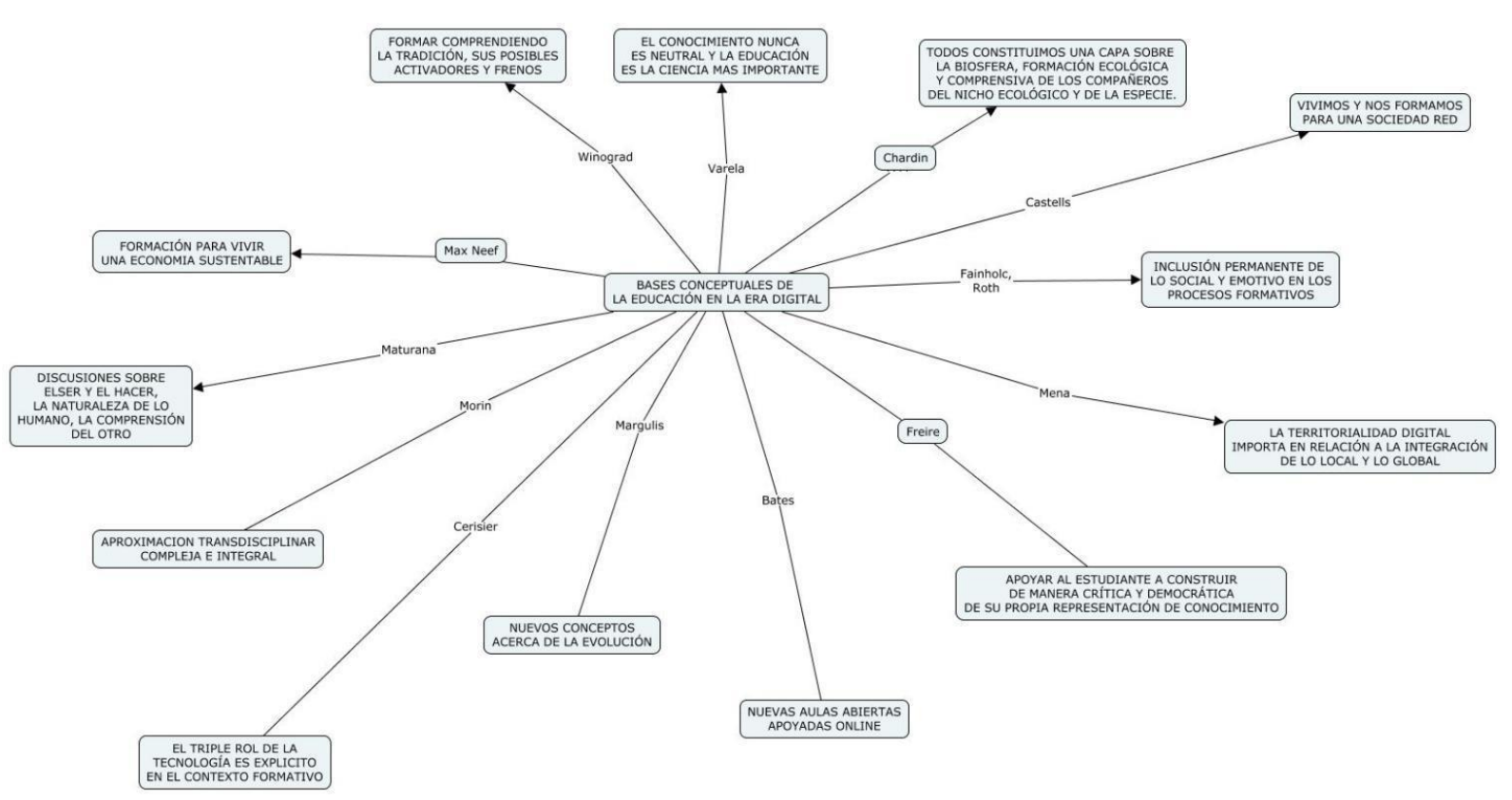

Fuente: Autores.

Fig. 7- Bases epistemológicas de una educación para una Era Digital humana

\section{Palabras Finales}

Pretendemos hacer una propuesta que puede tener aspectos incompletos o faltantes, que puede ser enriquecida de muchas maneras; es un comienzo para comenzar a plantearse la educación a futuro no de una manera ciega, sino basada en filósofos y pensadores que analizan los posibles futuros del desarrollo de nuestra especie.

En un mundo, del que sabemos que en dos o tres años cambiará el $40 \%$ de sus necesidades de trabajo (OCDE) y que a 20 años tendrá una fuerte participación de robots, bots y dispositivos de inteligencia artificial reemplazando muchos trabajos humanos, necesitamos proponer una educación que nos ayude a pasar de una etapa a otra de manera solidaria, una educación que entregue al estudiante conceptos acerca de la importancia de su desempeño para el desarrollo completo de su especie y a evitar los caminos que pueden llevar a su destrucción.

Esta Pandemia nos ha obligado a pensar aún más en la necesidades de contacto, de compartir sentimientos y sensaciones y desde ello podemos pensar propuestas educativas basadas en lo "humano" y no en el trabajo industrial como lo fue el trabajo de la sociedad 
industrial, concentrado en la obediencia, la disciplina, la repetición y la homogeneización de ciertas capas sociales.

Este momento es una oportunidad para aprovechar el potencial de lo digital en cada espacio del quehacer humano, para reinventarlo desde una perspectiva humana. Es el momento de mirar lo que teníamos de manera crítica para construir sin las limitaciones que nos ponía la situación anterior, y así mejorar las posibilidades para nuestras generaciones futuras.

San Luis, mayo 2020, en medio de la Pandemia.

\section{Bibliografía}

BALDIVIESO, Silvia. (2019). Diversidad, pluralismo epistémico e investigación en educación: más allá de lo instituido. Revista Otros Logos, Neuquén (Argentina): Universidad del Comahue. BATES, Tony. (2015). Teaching in a digital age. UBA, ISBN: 978-0-9952692-0-0. Buenos Aires.

BAUMAN, Zygmunt. (2000). Liquid Modernity. Londres: Polity Press y Blackwell Publishers. BOWLES, Samuel; GINTIS, Herbert. (1976). Schooling in capitalist America. New York: Haymarket Books.

CARRASCO, Selín, (2019). 12 Guias para enseñar en la Era Digital. San Luis (Argentina): Nueva Universidad.

CASTELLS, Manuel. (1997). Local y global. La gestión de las ciudades en la era de la información. Madrid: Taurus. (en colaboración con J. Borja).

CASTELLS, Manuel. (1999). La transformación del trabajo. Barcelona: Los Libros de la Factoría. (en colaboración con G. Esping-Andersen).

CASTELLS, Manuel. (2002). La era de la información. vol. I: La Sociedad Red. México, Distrito Federal: Siglo XXI.

CASTELLS, Manuel. (2001). La Era de la Información. vol. II: El poder de la identidad. México, Distrito Federal: Siglo XXI.

CASTELLS, Manuel. (2001). La Era de la Información. vol. III: Fin de Milenio. México, Distrito Federal: Siglo XXI.

CASTELLS, Manuel. La Galaxia Internet. (2001). Reflexiones sobre Internet, empresa y sociedad. Madrid: Areté.

CASTELLS, Manuel. (2002). The Information Age: economy, society and culture. vol. I: The rise of the network society. $2^{\text {nd }}$ ed. London: Blackwell Publishing.

CERISIER, Jean Francois. (2018). Les jeunes, le numérique et le monde en devenir. France Forum, $n^{\circ} 68$. Poitiers (France).

CERISIER, Jean-Francois. (2018). Médiation numérique des savoirs, éducation et formation. In: CPDirSIC, Dynamiques des recherches en sciences de l'information et de la communication, Acesso em : http://cpdirsic.fr/wp-content/uploads/2018/09/dynamiques-des$\underline{\text { recherches-sic-web-180919.pdf }}$ 
CERISIER, Jean.-Francois et alii. (2018). Rapport final à la Cour des comptes sur l'évaluation des politiques publiques pour le numérique éducatif à l'école élémentaire. Poitiers: Université de Poitiers (France).

CHARDIN, Teilhard. (1986). El fenómeno humano. Taurus, ISBN-10: 8430610324. Madrid.

FAINHOLC, Beatriz. (2003). La lectura crítica en internet, Revista: lectura y vida. Buenos Aires: Universidad Nacional de La Plata.

FAINHOLC, Beatriz. (2012). Una tecnología educativa apropiada y crítica: nuevos conceptos. 1. ${ }^{a}$ ed. Buenos Aires: Lumen Hvmanitas.

FREIRE, Paulo. (1989). La educación como práctica de la libertad. Introducción Francisco Weffort. $19^{\text {a }}$ ed. (1 ${ }^{\text {a }}$ ed., 1967). Río de Janeiro: Paz e Terra. 150 p.

FREIRE, Paulo. (1968). Educación y concienciación: extensionismo rural.: CIDOC / Cuaderno 25, 320p. Cuernavaca (México)

FREIRE, Paulo. (1970). Pedagogía del oprimido. New York: Herder y Herder, 1970 (manuscrito en portugués 1968). Publicado con el prefacio de Ernani Maria Fiori. Río de Janeiro: Continuum. 218 p.

KROPOTKIN, Piotr. (2016) 'El apoyo Mutuo. Un factor de la evolución. Introducción, ISBN 9781530556946, Barcelona: Createspace Independent Publishing Platform.

LAVAGNINO, Nicolás José; MASSARINI, Alicia; FOLGUERA, Guillermo. (2014). Simbiosis y Evolución. Un análisis de las implicaciones evolutivas de la simbiosis en la obra de Lynn Margulis, Revista Colombiana de Filosofía de la Ciencia, Bogotá: Universidad El Bosque, vol. 14, n. 29, jul./dic. 2014.. p.161-181.

MATURANA, Humberto; VARELA, Francisco. (2009). El árbol del conocimiento: las bases biológicas del entendimiento humano $19^{\mathrm{a}}$ ed. Santiago de Chile: Universitaria.

NEEF, Manfred Max. (1986). Desarrollo a escala humana: conceptos, aplicaciones y reflexiones. Barcelona: Icaria Editorial, ISBN 978-84-7426-217-9. 2013. Buenos Aires: Biblioteca Permacultura.

MENA, Marta et alii. (2005). El diseño de proyectos de educación a distancia. Buenos Aires: Stella/La Crujía.

MORIN, Edgar; GONZÁLEZ, Mario Soto. (1999). Complejidad y sujeto humano, ISBN 84688-1185-8, Valladolid: Universidad de Valladolid, disponible en Biblioteca Virtual Miguel de Cervantes.

CIURANA, Emilio Roger; MORIN, Edgar. (1997). Introducción al pensamiento complejo. ISBN 978-84-7762-765-4, Valladolid: Universidad de Valladolid, Secretariado de Publicaciones, correo electrónico: secretariado.publicaciones@uva.es, Página Web.

DA CONCEIÇAO DE ALMEIDA, María. (2006). Para comprender la complejidad. ISBN 978-968-9330-01, GRECOM/UFRN, 2006, disponible en Sitio Oficial del Profesor Morin.

MARGULIS, Lynn. (2003). Una revolución en la evolución: escritos seleccionados. Colección Honoris Causa. Valencia: Universitat de Valencia. p. 374 p. ISBN 978-84-370-5494-0. Valencia (España).

SZEKELY, E.; MASON, M. (2018). Complexity theory, the capability approach, and the sustainability of development initiatives in education. Journal of Education Policy.: Brighton (UK). Taylor y Francis. doi:10.1080/02680939.2018.1465999. 
VARELA, Francisco. (1998). Conocer. Colección "EL mamífero parlante”, Gedisa. Barcelona: VIRILIO, Paul. (2005). Negative Horizon: an essay in dromoscopy. London: Continuum.

WINOGRAD, Terry; Fernando Flores. (1987). Understanding computers and cognition: a new foundation for design, (1987) Norwood (NJ): Ablex, Paperback issued by Addison-Wesley. 220 p. 